\title{
Recording COVID-19 consultations: review of symptoms, risk factors, and proposed SNOMED CT terms
}

\section{Bhautesh Dinesh Jani ${ }^{1 *}$, Jill P Pell ${ }^{2}$, Dylan McGagh ${ }^{3}$, Harshana Liyanage ${ }^{4}$, Dave Kelly ${ }^{5}$, Simon de Lusignan ${ }^{6}$, Christopher J Weatherburn ${ }^{7}$, Ronnie Burns ${ }^{8}$, Frank M Sullivan', Frances S Mair ${ }^{10}$}

${ }^{1}$ Clinical Senior Lecturer in General Practice and Primary Care, Institute of Health and Wellbeing, University of Glasgow, Glasgow, UK; ${ }^{2}$ Henry Mechan Professor of Public Health, Institute of Health and Wellbeing, University of Glasgow, Glasgow, UK; ${ }^{3}$ Medical Sciences Divison, University of Oxford, Oxford, UK; ${ }^{4}$ Nuffield Department of Primary Care Health Sciences, University of Oxford, Oxford, UK; ${ }^{5}$ Albasoft Limited, Centre for Health Science, Inverness, UK; ${ }^{6}$ Professor of Primary Care and Clinical Informatics, Nuffield Department of Primary Care Health Sciences, University of Oxford, Oxford, UK; ${ }^{7}$ Scottish Clinical Information Management in Practice, National Services Scotland, Edinburgh, UK; ${ }^{8}$ McKenzie Burns Practice, Parkhead Health Centre, Glasgow, UK; ${ }^{9}$ Professor of Primary Care Medicine, Medical School, University of St Andrews, St Andrews, UK; ${ }^{10}$ Norie Miller Professor of General Practice, Institute of Health and Wellbeing, University of Glasgow, Glasgow, UK

\begin{abstract}
Background: There is an urgent need for epidemiological research in primary care to develop risk assessment processes for patients presenting with COVID-19, but lack of a standardised approach to data collection is a significant barrier to implementation.
\end{abstract}

Aim: To collate a list of relevant symptoms, assessment items, demographics, and lifestyle and health conditions associated with COVID-19, and match these data items with corresponding SNOMED CT clinical terms to support the development and implementation of consultation templates.

*For correspondence: bhautesh. jani@glasgow.ac.uk

Competing interest: See page 7

Received: 29 May 2020

Accepted: 10 July 2020

Published: 26 August 2020

(C)This article is Open Access: CC BY license (https://creativecommons.org/licenses/by/4.0/)

Author Keywords: COVID-19, Systematised Nomenclature of Medicine, General practice, Primary health care, Medical Records Systems, Computerised

Copyright (C) 2020, The Authors; DOI:10.3399/

bjgpopen20X101125
Design \& setting: Published and preprint literature for systematic reviews, meta-analyses, and clinical guidelines describing the symptoms, assessment items, demographics, and/or lifestyle and health conditions associated with COVID-19 and its complications were reviewed. Corresponding clinical concepts from SNOMED CT, a widely used structured clinical vocabulary for electronic primary care health records, were identified.

Method: Guidelines and published and unpublished reviews $(N=61)$ were utilised to collate a list of relevant data items for COVID-19 consultations. The NHS Digital SNOMED CT Browser was used to identify concept and descriptive identifiers. Key implementation challenges were conceptualised through a Normalisation Process Theory (NPT) lens.

Results: In total, 32 symptoms, eight demographic and lifestyle features, 25 health conditions, and 20 assessment items relevant to COVID-19 were identified, with proposed corresponding SNOMED CT concepts. These data items can be adapted into a consultation template for COVID-19. Key implementation challenges include: 1) engaging with key stakeholders to achieve 'buy in'; and 2) ensuring any template is usable within practice settings.

Conclusion: Consultation templates for COVID-19 are needed to standardise data collection, facilitate research and learning, and potentially improve quality of care for COVID-19. 


\section{How this fits in}

Recording of clinical features of COVID-19 presentation in primary care is likely to be poor in the absence of a template. A rapid literature review was therefore conducted to collate a comprehensive list of symptoms, assessment items, demographics, and lifestyle and health conditions associated with COVID-19, with proposed corresponding SNOMED CT clinical terms. The evidence base around COVID-19 is rapidly evolving and this list may have to be updated in the future as new evidence becomes available. These data items can be adapted into a consultation template to standardise data collection, which in turn can facilitate research and improve quality of record keeping. In practice, there are often multiple SNOMED CT clinical terms for recording a single data item. A professional consensus will be needed among clinician users to agree on appropriate SNOMED CT clinical terms to be used in a template. Implementation and widespread use of a COVID-19 consultation template will need positive engagement with key stakeholders.

\section{Introduction}

The COVID-19 pandemic is an unprecedented global health challenge. Understanding of the epidemiology and clinical features of COVID-19 is rapidly evolving. New evidence is constantly emerging, with articles being published or uploaded on preprint servers regularly and various public health bodies, nationally and internationally, releasing their respective guidelines.

COVID-19 consultations in primary care are further complicated by contextual factors. In the UK, most of the consultations for patients with COVID-19 related symptoms are conducted remotely. ${ }^{1-3}$ This usually involves more than one screen being used at the same time, which makes it challenging for GPs to accurately recall and record all relevant clinical features during their consultation with patients with suspected COVID-19 symptoms. When the consultation is in-person in the surgery, personal protective equipment (PPE) restricts normal recording patterns, and this is even worse during home visits.

Good quality epidemiological studies are urgently needed to understand COVID-19. ${ }^{4}$ Most of the epidemiological studies until now have been conducted in secondary care. ${ }^{5}$ There is an urgent need for high-quality primary care epidemiological studies for COVID-19. Recently, the use of COVID-19 specific codes have been recommended but these codes mainly cover process measures and diagnostic terms, not clinical presentation features such as symptoms and assessment. ${ }^{6,7}$ Previous research has suggested that only $37 \%$ of clinical problems were coded in primary care records. ${ }^{8}$ Underreporting of relevant clinical features for COVID-19 in primary care is likely during COVID-19 related consultations, which will be a significant hindrance for high quality primary care research. A computerised, conditionspecific template has previously been shown to improve the quality of care and recording in primary care, and it could be implemented for COVID-19. ${ }^{9}$

The aim of this study was to collate a list of relevant symptoms, assessment items, demographics, and lifestyle and health conditions associated with COVID-19 and its complications, and match these data items with proposed examples of corresponding SNOMED CT clinical terms, which will support the development and implementation of primary care consultation templates. The clinical utility of any template developed based on this work will be to help clinicians record consultations for patients presenting with suspected COVID-19 related symptoms in primary care.

\section{Method}

The review of clinical terms involved three distinct stages: 1) search of clinical guidelines, and published and preprint literature to collate the list of relevant clinical data items for COVID-19 consultation; 2) identify examples of corresponding SNOMED CT codes that map to the identified clinical data items; and 3) conceptualise implementation challenges through an NPT lens.

\section{Search for clinical data items for COVID-19}

The authors searched PubMed, the preprint server medRxiv, and centre for evidence-based medicine websites for reviews using 'COVID-19' as a keyword on 14 May 2020. The PubMed search resulted in 963 articles, while 548 articles were found on preprint server medRxiv. The inclusion criteria were systematic reviews and meta-analyses relating to symptoms, sociodemographic and lifestyle 
factors, past medical history, and assessment of COVID-19. As the focus was related to primary care assessment, reviews relating to blood tests and imaging for COVID-19 were excluded. Twentyone systematic reviews on preprint servers and 24 published systematic reviews from PubMed were identified. The authors searched for COVID-19 related guidelines on Public Health England, Health Protection Scotland, Public Health Wales, British Medical Journal (BMJ), Royal College of General Practitioners (RCGP), National Institute for Health and Care Excellence (NICE), and World Health Organization (WHO) websites. Sixteen clinical guidelines were considered for collating the list of COVID-19 consultation data items described above.

\section{Search for corresponding clinical terms for COVID-19}

SNOMED CT is the most comprehensive structured clinical terminology in use around the world and can be used in electronic health records (http://www.snomed.org/snomed-ct/why-snomed-ct). This international clinical terminology has been implemented across various health and care settings, including primary and secondary care. Principles outlined in Data Quality Guidance: Transitioning from Read to SNOMED CT by NHS Digital were used for choosing examples of proposed SNOMED CT clinical terms. ${ }^{10}$ First, the authors referred to appropriate SNOMED hierarchies, for example, 'disorders' or 'situation' for recording health conditions, and 'finding' or 'observable entity' for recording symptoms and signs. Only SNOMED CT codes that had equivalent Read codes were considered, as Read codes are still in use in general practice in Scotland. Codes that were regarded as 'inactive' and no longer in use were also excluded. SNOMED CT UK edition (version 20200415) was interrogated by the NHS Digital web browser to search for terms and identifiers for each of the clinical data items identified from the previous step. Additionally, the SNOMED CT code identified was matched to the corresponding Read version 2 codes using NHS Digital browser. ${ }^{11}$

Table 1 Symptoms and assessment items relevant for COVID-19 primary care consultation with respective SNOMED CT concept identifiers

\begin{tabular}{|c|c|}
\hline $\begin{array}{l}\text { Imptoms (with respective SNOMED CT concept } \\
\text { entifiers) }\end{array}$ & $\begin{array}{l}\text { Primary care assessment (with respective SNOMED } \\
\text { CT concept identifiers) }\end{array}$ \\
\hline $\begin{array}{l}\text { 1. Date of onset of symptoms SCTID: } 520191000000103 \\
\text { 2. H/O fever SCTID: } 866621000000103 \text { (common) } \\
\text { 3. C/O cough SCTID: } 272039006 \text { (common) } \\
\text { 4. Productive cough SCTID: } 28743005 \text { (common) } \\
\text { 5. Fatigue-symptom (finding) SCTID: } 272060000 \\
\text { (common) } \\
\text { 6. Myalgia/muscle pain SCTID: } 68962001 \text { (common) } \\
\text { 7. Dyspnoea SCTID: } 267036007 \text { (common) } \\
\text { 8. Has a sore throat SCTID: } 162388002 \text { (common) } \\
\text { 9. C/O anosmia SCTID: } 272028008 \text { (common) } \\
\text { 10. C/O loss of taste sense SCTID: } 272041007 \text { (common) } \\
\text { 11. Bloodstained sputum SCTID } 61281005 \\
\text { 12. Chest pain SCTID: 29857009 } \\
\text { 13. Joint pain SCTID: } 57676002 \\
\text { 14. C/O shivering SCTID: } 161855003 \\
\text { 15. Dizziness SCTID: } 404640003 \\
\text { 16. C/O a headache SCTID: } 272027003 \\
\text { 17. H/O disturbance of consciousness SCTID: } \\
\text { 91111000000108 } \\
\text { 18. Convulsion SCTID: } 91175000 \\
\text { 19. Syncope symptom SCTID: } 272030005 \\
\text { 20. Nausea SCTID: 4225870071 } \\
\text { 21. C/O vomiting SCTID: } 272044004 \\
\text { 22. Loss of appetite SCTID: } 79890006 \\
\text { 23. Diarrhoea SCTID: 62315008 } \\
\text { 24. Abdominal pain SCTID: } 21522001 \\
\text { 25. Gastrointestinal haemorrhage SCTID: } 74474003 \\
\text { 26. Nasal symptoms SCTID: } 249307003 \\
\text { 27. Rhinorrhoea SCTID: 64531003 } \\
\text { 28. C/O nasal congestion SCTID: } 272034001 \\
\text { 29. Respiratory symptom SCTID: } 161920001 \\
\text { 30. Red eye SCTID: } 703630003 \\
\text { 31. C/O a rash SCTID: } 162415008 \\
\text { 32. Palpitations SCTID: } 80313002\end{array}$ & $\begin{array}{l}\text { 1. Rockwood Clinical Frailty Scale SCTID: } 445414007 \\
\text { 2. Dyspnoea on exertion SCTID: } 60845006 \\
\text { 3. Breathless at rest (finding) SCTID: } 161941007 \\
\text { 4. Ability to perform activities of everyday life SCTID: } \\
\text { 284545001 } \\
\text { 5. Unable to climb stairs SCTID: } 165247006 \\
\text { 6. Normal fluid intake SCTID: } 161843009 \\
\text { 7. Not taking fluids (finding) SCTID: } 161845002 \\
\text { 8. Oliguria SCTID: } 83128009 \\
\text { 9. Anuria (finding) SCTID: } 2472002 \\
\text { 10. Unable to stand (finding) SCTID: } 161903000 \\
\text { 11. C/O cold extremities SCTID: } 161996001 \\
\text { 12. Blue lips (finding) SCTID: } 162743000 \\
\text { 13. Mentally alert SCTID: } 248234008 \\
\text { 14. O/E confused SCTID: } 162702000 \\
\text { 15. O/E disorientated SCTID: } 163608000 \\
\text { Vital Observations (if available) } \\
\text { 16. O/E temperature (observable entity) SCTID: } \\
\text { 309646008 } \\
\text { 17. O/E pulse rate SCTID: } 162986007 \\
\text { 18. Peripheral oxygen saturation SCTID: } 431314004 \\
\text { 19. O/E blood pressure reading SCTID: } 163020007 \\
\text { 20. O/E respiratory rate SCTID: } 162913005\end{array}$ \\
\hline
\end{tabular}

$\mathrm{C} / \mathrm{O}=$ complains of. $\mathrm{H} / \mathrm{O}=$ history of. $\mathrm{O} / \mathrm{E}=$ on examination. SCTID $=$ SNOMED CT Identifier 


\section{Conceptualising implementation of consultation template}

GP consultation templates are often viewed as less patient-centred and potentially disruptive to communication. ${ }^{12}$ The majority of existing consultation templates are used for management of longterm conditions; however, they have also been used for recording management of acute infections. ${ }^{13}$ Widespread adaptation of a template in a short timeframe can provide significant implementation challenges. An NPT lens was used to conceptualise these challenges and corresponding key strategies to deal with those challenges. ${ }^{14}$

\section{Results}

\section{Clinical data items and SNOMED CT codes}

In total, searches identified 32 symptoms associated with COVID-19 presentation from 10 guidelines, ${ }^{1,3,15-22} 13$ published reviews, ${ }^{23-35}$ and 12 preprint reviews. ${ }^{36-47}$ See Table 1 for the list of symptoms and proposed corresponding SNOMED CT codes. The symptoms of COVID-19 were heterogenous in nature and included flu-like; respiratory; gastrointestinal; central nervous system; ear, nose, and throat; and eye symptoms reported in the literature.

The clinical domain of primary care assessment for COVID-19 had the least number of supporting reviews (two preprint reviews) ${ }^{39,48}$ and the majority of the data items included were on the basis of clinical guidelines, ${ }^{1-3,16-20,49,50}$ which in turn were based on expert opinions (Table 1). The data items included for COVID-19 assessment were based on data items validated for general practice consultations, but not specifically for COVID-19 (for example, telephone consultation for suspected sepsis $^{49}$ and use of the NEWS2 tool ${ }^{1}$ ).

Demographic factors (age, sex, and ethnicity) were reported to be relevant for COVID-19 susceptibility and complications by two guidelines, ${ }^{15,20} 10$ published reviews, ${ }^{5,25,26,28,30,33,51-54}$ and seven preprint reviews. ${ }^{37,43,55-59}$ Lifestyle factors (working, smoking, and body mass index) were reported to be relevant for COVID-19 related assessment by two guidelines, ${ }^{15,20}$ one published review, ${ }^{51}$ and

Table 2 Demographic, lifestyle, and existing health conditions relevant for COVID-19 primary care consultations

\begin{tabular}{ll}
\hline $\begin{array}{l}\text { Lifestyle and demographics (with respec- } \\
\text { tive SNOMED CT concept identifiers) }\end{array}$ & $\begin{array}{l}\text { Past medial history (PMH) relevant for COVID-19 primary care } \\
\text { consultation (with respective SNOMED CT concept identifiers) }\end{array}$ \\
\hline 1. Age & 1. High-risk category for developing complication from COVID-19 \\
2. Sex & infection SCTID: 1300561000000107 \\
3. Ethnicity/related nationality data & 2. H/O diabetes mellitus SCTID: 161445009 \\
(observable entity) SCTID: 186034007 & 3. H/O hypertension SCTID: 161501007 \\
4. Health profession SCTID: 223366009 & 4. Ischaemic heart disease SCTID: 414545008 \\
5. Current smoker SCTID: 77176002 & 5. H/O heart failure SCTID: 161505003 \\
6. Ex-smoker SCTID: 8517006 & 6. Rheumatic heart disease SCTID: 23685000 \\
7. Non-smoker SCTID: 8392000 & 7. H/O atrial fibrillation SCTID: 312442005 \\
8. Finding of body mass index SCTID: & 8. Cardiac arrhythmia SCTID: 698247007 \\
301331008 & 9. Congenital heart disease SCTID: 13213009 \\
& 10. Pulmonary heart disease SCTID: 274096000 \\
& 11. H/O asthma SCTID: 161527007 \\
& 12. History of chronic obstructive pulmonary disease SCTID: \\
& 270473001 \\
13. Pulmonary emphysema SCTID: 87433001 \\
14. H/O bronchiectasis SCTID: 939431000000108 \\
15. Cystic fibrosis SCTID: 190905008 \\
16. Pulmonary fibrosis SCTID: 51615001 \\
17. Chronic kidney disease SCTID: 709044004 \\
18. Chronic liver disease SCTID: 328383001 \\
19. H/O stroke SCTID: 275526006 \\
20. H/O epilepsy SCTID: 161480008 \\
21. H/O dementia SCTID: 161465002 \\
22. Multiple sclerosis SCTID: 24700007 \\
23. Motor neurone disease SCTID: 37340000 \\
24. Patient immunocompromised SCTID: 370388006 \\
25. Pregnant SCTID: 77386006 \\
\hline
\end{tabular}

Information on age and sex is usually documented on all electronic primary care records and is not needed in a consultation template. $\mathrm{H} / \mathrm{O}=$ history of. SCTID = SNOMED CT Identifier. 
seven preprint reviews. ${ }^{37,43,55-57,59,60}$ Individuals working in the health profession were regarded as high risk by one guideline. ${ }^{20}$ See Table 2 for the list of relevant demographics and lifestyle factors, and examples of corresponding SNOMED CT codes (apart from clinical terms for age and sex, which are usually recorded in all primary care records).

In total, 25 health conditions were identified with COVID-19 vulnerability and/or complications, reported by two guidelines, ${ }^{15,20} 16$ published reviews ${ }^{5,25-28,30-33,54,61-66}$ and 10 preprint reviews. ${ }^{37,39,42,45,47,57,59,60,67,68}$ The list of conditions included the 'high-risk' or 'extremely vulnerable from COVID-19' criteria based on guidelines issued by Public Health England and Health Protection Scotland. ${ }^{69,70}$ The list included a breadth of conditions ranging from cardiovascular, respiratory, immunosuppressed conditions, and previous cancer (see Table 2 for the list of medical conditions and the proposed examples of corresponding SNOMED CT codes). The mapping Read version 2 codes for the SNOMED CT codes identified are listed in Supplementary file Tables S1-4.

\section{Implementation challenges and solutions}

There is an extensive literature regarding barriers and facilitators to digital health implementation. ${ }^{71}$ This literature has demonstrated the importance of considering implementation issues whenever introducing any new digital health system, including those relating to electronic medical record systems. ${ }^{72}$ While electronic medical record systems are fully integrated within general practice in the UK, changes to functionality or uptake and utilisation of new templates within electronic medical record systems may not become widespread unless potential barriers or facilitators to use are considered. ${ }^{73}$ NPT is a theory of implementation that has been used extensively over the last decade to understand how new service innovations, particularly digital health innovations, can become embedded and implemented, or not, as part of routine practice. ${ }^{14}$ It suggests the need to consider issues relating to: coherence, how people make sense of a new way of working; cognitive participation, the engagement work required to get people to 'buy into' adopting a new way of working; collective action, the work of operationalising a new digital tool; and reflexive monitoring, the work of appraising, judging, or adapting a new digital innovation. There is evidence that considering and addressing such issues at the start of any new digital intervention will enhance the likelihood of routine embedding as part of normal practice. Table 3 outlines key issues that should be addressed in order to enhance uptake and utilisation of any new COVID-19 template. As a proof of concept, a COVID-19 consultation

Table 3 Key Normalisation Process Theory-informed implementation issues to consider when introducing a new COVID-19 template

\begin{tabular}{|c|c|}
\hline Coherence & $\begin{array}{l}\text { Ensuring that potential users are aware of the new } \\
\text { template and that they understand the rationale for } \\
\text { trying to promote utilisation with every COVID-19 } \\
\text { patient. }\end{array}$ \\
\hline Cognitive participation & $\begin{array}{l}\text { Engagement with users will be key to ensure they will } \\
\text { invest time using the template. } \\
\text { Ensuring that the use of the template should assist } \\
\text { primary care clinicians in recording relevant clinical items } \\
\text { rather than act as a hindrance or source of additional } \\
\text { work. } \\
\text { Ensuring users are clear that the items included in the } \\
\text { template are evidence based and that it is clinically } \\
\text { worthwhile to record the data items within the template. } \\
\text { Champions within the GP workforce can be valuable to } \\
\text { promote uptake. }\end{array}$ \\
\hline Collective action & $\begin{array}{l}\text { Any template needs to be easy to navigate and use. } \\
\text { A template that is too time-consuming to complete is } \\
\text { unlikely to achieve widespread utilisation. Consequently, } \\
\text { any template needs to be embedded in the currently } \\
\text { used electronic medical record system. }\end{array}$ \\
\hline Reflexive monitoring & $\begin{array}{l}\text { Providing feedback to users regarding data collected } \\
\text { from the template will enable them to see the potential } \\
\text { benefits and learning that can be gained through use of } \\
\text { the template. Providing a mechanism to allow iterative } \\
\text { feedback so that the template can be improved in line } \\
\text { with user comments would also be important. }\end{array}$ \\
\hline
\end{tabular}




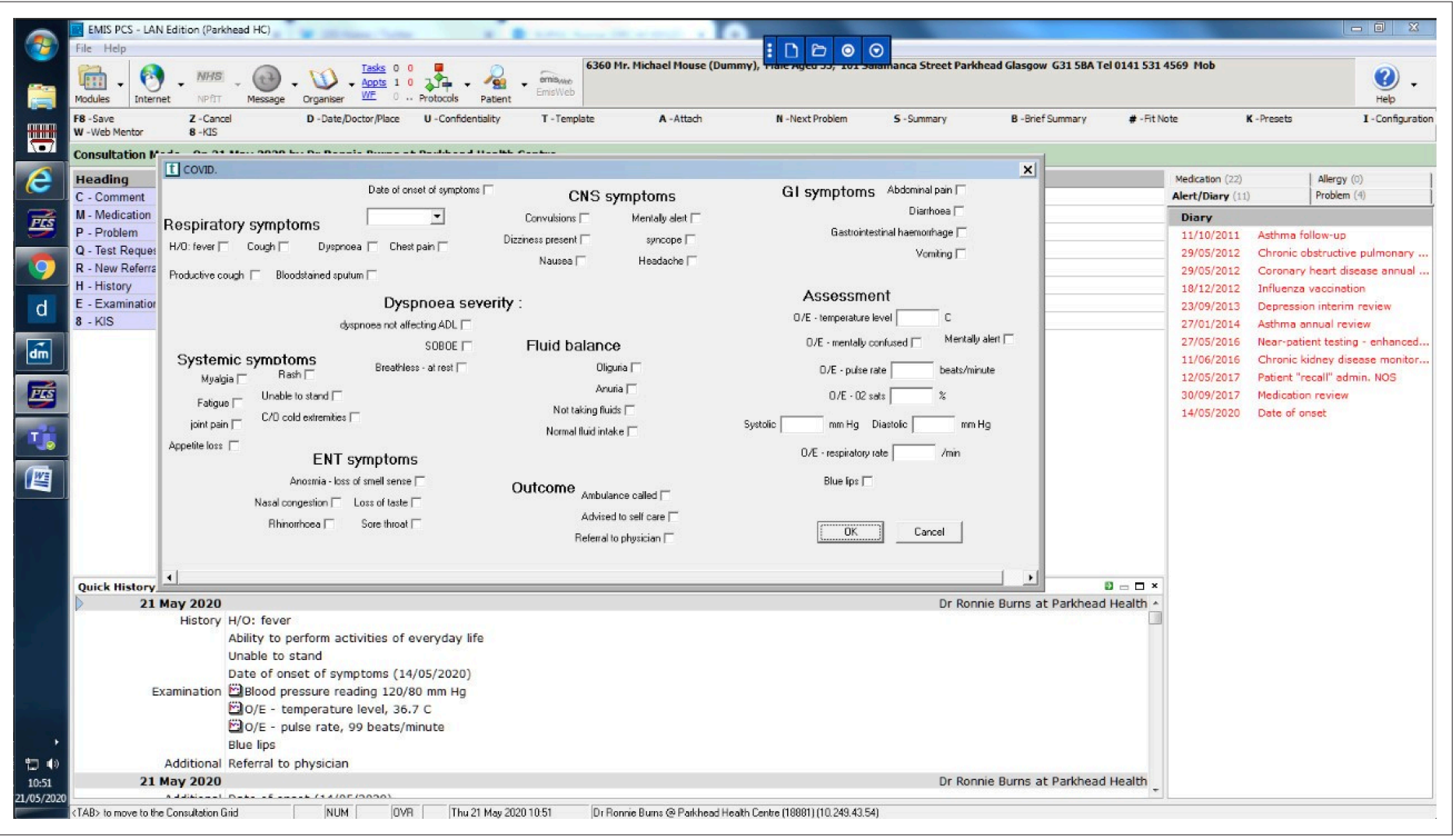

Figure 1 A consultation template prototype in EMIS with symptoms and assessment items for recording COVID-19 consultations in primary care

template prototype using data items relevant for symptoms and assessment was developed at a practice level in EMIS (Figure 1). Such consultation template prototypes may have to be modified after operationalisation, based on user feedback.

\section{Discussion}

The authors identified 32 symptoms, 20 assessment items, eight demographic and lifestyle features, and 25 health conditions relevant for recording in COVID-19 primary care consultations. The supporting evidence base for these data items comprised of 16 clinical guidelines, 24 published, and 21 unpublished systematic reviews. The authors propose examples of corresponding clinical terms for all clinical data items from the SNOMED CT browser, which can be used to develop consultation templates for different primary care IT system providers. The authors also discuss the likely implementation challenges and potential solutions for large scale roll out of a COVID-19 consultation template. The contents of any COVID-19 consultation template may have to be adapted in future as knowledge and understanding evolves.

\section{Strengths and limitations}

This is the first study to collate a list of relevant clinical items and corresponding clinical terms for COVID-19 consultation. The search for preprint servers enabled the authors to include the most upto-date evidence, with the caveat that these platforms publish rapid non-peer reviewed literature. This study also outlines an implementation blueprint using a well-known theoretical framework for complex interventions.

There are several limitations. First, the authors did not employ a systematic search strategy for the literature review, and did not conduct a quality appraisal of the included studies as these were not the objectives of this study. The study objective was to facilitate standardised data collection, which in turn can lead to high quality research and strengthen the evidence base. Several data items were included 
from preprint studies that have not undergone the scrutiny of peer review, and future evidence may suggest that recording of these data items is not necessary for risk assessment in primary care.

\section{Comparison with existing literature}

Implementation of a COVID-19 consultation template is likely to face similar challenges to those observed with implementation of other general practice consultation templates. The previous positive experiences with the use of a template have included providing a structured consultation and being more comprehensive, while the use of a template has also been perceived as less patient-centred and more focused on a biomedical agenda. ${ }^{12,74,75}$ The uptake of a template in clinical practice is not likely to be universal; clinicians may need prompting and the template may require reinforcing to improve utilisation. ${ }^{13}$ There have been very few primary care-based studies of COVID-19, and these studies have not been able to report on symptoms or assessment due to inconsistencies in recording of symptoms in primary care. ${ }^{76,77}$

\section{Implications for research and practice}

The list of clinical terms can lead to the development of COVID-19 consultation templates, which in turn will help with standardised data collection and high quality research. A consultation template can potentially help with quality of clinical care and record keeping by facilitating comprehensive coverage of various clinical domains relevant to COVID-19. ${ }^{78}$ The use of a consultation template along with coding of other process measures included in the recently published ontology ${ }^{79}$ and SNOMED CT codes on COVID-19 released by NHS Digital ${ }^{80}$ can also help with disease surveillance. Several data items related to demographics, lifestyle, and past medical history may already be recorded in patient's existing primary care records. These items are still included in the template as they will be relevant in out-of-hours settings where this information may not be readily available. The authors acknowledge that the codes presented are only examples for recording the relevant clinical data items. In practice, there are often multiple ways of recording a single data item and previous research has suggested evidence of considerable heterogeneity in SNOMED CT coding. ${ }^{81,82}$ A professional consensus exercise will be needed among clinician users to agree on appropriate SNOMED CT clinical terms. The use of a COVID-19 consultation template has the potential to offer consistency in data collection, albeit with some variations in codes used to record clinical data items.

\section{Funding}

There are no funders to report for this article.

Ethical approval

No ethical approval was required.

Provenance

Freely submitted; externally peer reviewed.

Competing interests

SdeL is Director of the Royal College of General Practitioners, Research and Surveillance Centre (English national surveillance system). SdeL has received commercial funding for investigator led research, and belongs to advisory boards, but not related to COVID-19 and all through his university.

\section{References}

1. National Institute for Health and Care Excellence. COVID-19 rapid guideline: managing suspected or confirmed pneumonia in adults in the community. NG165. 2020; https://www.nice.org.uk/guidance/ng165 (accessed 13 Aug 2020).

2. Greenhalgh T, Koh GCH, Car J. Covid-19: a remote assessment in primary care. BMJ 2020; 368:.m1182. DOI: https://doi.org/10.1136/bmj.m1182

3. Royal College of General Practitioners. Guide to triaging patients with potential symptoms. 2020; https://elearning. rcgp.org.uk/mod/page/view.php?id=10704 (accessed 13 Aug 2020).

4. Lipsitch M, Swerdlow DL, Finelli L. Defining the epidemiology of Covid-19 — studies needed. N Engl J Med 2020; 382(13): 1194-1196. DOI: https://doi.org/10.1056/NEJMp2002125 
5. Wynants L, Van Calster B, Collins GS, et al. Prediction models for diagnosis and prognosis of covid-19 infection: systematic review and critical appraisal. BMJ 2020; 369: m1328. DOI: https://doi.org/10.1136/bmj.m1328

6. de Lusignan S, Williams J. To monitor the COVID-19 pandemic we need better quality primary care data. BJGP Open 2020; 4(2): bjgpopen20X101070. DOI: https://doi.org/10.3399/bjgpopen20X101070

7. Faculty of Clinical Informatics. COVID-19 coding in primary care. 2020; https://facultyofclinicalinformatics.org.uk/ web/content/1607? ?nique $=425692 a 55 f 2018 b 717232 f 96407 b 66 f 158 c 6 d 52 c \& d o w n l o a d=t r u e$ (accessed 13 Aug 2020).

8. Salisbury $\mathrm{C}$, Procter $\mathrm{S}$, Stewart $\mathrm{K}$, et al. The content of general practice consultations: cross-sectional study based on video recordings. Br J Gen Pract 2013; 63(616): e751-e759. DOI: https://doi.org/10.3399/bjgp13X674431

9. Fung $\mathrm{CH}$. Computerized condition-specific templates for improving care of geriatric syndromes in a primary care setting. J Gen Intern Med 2006; 21(9): 989-994. DOI: https://doi.org/10.1007/BF02743150

10. NHS Digital. Data Quality Guidance: transitioning from Read to SNOMED CT. Version 5. 2019; https://hscic. kahootz.com/gf2.ti/f/762498/54542725.1/DOCX/-/Data_Quality_Guidance_for_Primary_Care_v2.docx (accessed 13 Aug 2020).

11. NHS Digital. Read v2 to SNOMED CT mapping lookup (April 2020). 2020; https://hscic.kahootz.com/connect.ti/ t_c_home/viewdatastore?dsid=407588\&adv=S\&showAllColumns=N\&datViewMode=list\&showSingleltem=N\& cardColNo= (accessed 13 Aug 2020)

12. Swinglehurst $D$, Greenhalgh $T$, Roberts $C$. Computer templates in chronic disease management: ethnographic case study in general practice. BMJ Open 2012; 2(6): e001754. DOI: https://doi.org/10.1136/bmjopen-2012-001754

13. Chen C, Crowley R. Improving assessment of children with suspected respiratory tract infection in general practice. BMJ Open Qual 2019; 8(2): e000450. DOI: https://doi.org/10.1136/bmjoq-2018-000450

14. May CR, Cummings A, Girling M, et al. Using Normalization Process Theory in feasibility studies and process evaluations of complex healthcare interventions: a systematic review. Implement Sci 2018; 13(1): 80. DOI: https:// doi.org/10.1186/s13012-018-0758-1

15. BMJ Best Practice. Coronavirus disease 2019 (COVID-19). 2020; https://bestpractice.bmj.com/topics/en-gb/ 3000168 (accessed 13 Aug 2020).

16. Public Health England. COVID-19: investigation and initial clinical management of possible cases. 2020; https:// www.gov.uk/government/publications/wuhan-novel-coronavirus-initial-investigation-of-possible-cases/investigationand-initial-clinical-management-of-possible-cases-of-wuhan-novel-coronavirus-wn-cov-infection (accessed 13 Aug 2020).

17. Public Health Wales. (COVID-19) INTERIM guidance for primary care management of patients presenting to primary care. 2020; https://phw.nhs.wales/topics/latest-information-on-novel-coronavirus-covid-19/information-forhealthcare-workers-in-wales/180320-interim-primary-care-guidance-covid19 (accessed 13 Aug 2020).

18. Razai MS, Doerholt K, Ladhani S, et al. Coronavirus disease 2019 (covid-19): a guide for UK GPs. BMJ 2020; 368:.m800. DOI: https://doi.org/10.1136/bmj.m800

19. Scottish Government. COVID-19 Scottish primary care hub triage guide. 2020; https://www.gov.scot/binaries/ content/documents/govscot/publications/advice-and-guidance/2020/04/coronavirus-covid-19-clinical-advice/ documents/covid-19-cmo-clinical-advice-primary-care-hub-triage-guide/covid-19-cmo-clinical-advice-primary-carehub-triage-guide/govscot\%3Adocument/COVID-19\%2BCMO\%2Bclinical\%2Bguidance\%2B-\%2Bappendix\%2B1-\% 2BScottish\%2Bprimary\%2Bcare\%2Bhub\%2Btriage\%2Bguide\%2B-\%2B3\%2BApril\%2B2020.pdf (accessed 18 Aug 2020).

20. World Health Organization. International Severe Acute Respiratory and Emerging Infection ConsortiumCase record form instructions: severe acute respiratory infection clinical characterisation data tools. 2020; https://media.tghn. org/medialibrary/2016/06/ISARIC-WHO-SARI_Case_Record_Form_7JAN16.pdf (accessed 13 Aug 2020).

21. Healthcare Improvement Scotland. Assessment of COVID-19 in primary care. 2020; https://www.sign.ac.uk/ourguidelines/assessment-of-covid-19-in-primary-care/ (accessed 13 Aug 2020).

22. Struyf $T$, Deeks JJ, Dinnes J, et al. Signs and symptoms to determine if a patient presenting in primary care or hospital outpatient settings has COVID-19 disease. Cochrane Database Syst Rev 2020; 7(7): CD013665 DOI: https://doi.org/10.1002/14651858.CD013665

23. Ludvigsson JF. Systematic review of COVID-19 in children shows milder cases and a better prognosis than adults. Acta Paediatr 2020; 109(6): 1088-1095. DOI: https://doi.org/10.1111/apa.15270

24. Hu Y, Sun J, Dai Z, et al. Prevalence and severity of corona virus disease 2019 (COVID-19): a systematic review and meta-analysis. J Clin Virol 2020; 127: 104371. DOI: https://doi.org/10.1016/j.jcv.2020.104371

25. Zheng Z, Peng F, Xu B, et al. Risk factors of critical \& mortal COVID-19 cases: a systematic literature review and meta-analysis. J Infect 2020; 81(2): e16-e25. DOI: https://doi.org/10.1016/j.jinf.2020.04.021

26. Cao Y, Liu X, Xiong L, Cai K. Imaging and clinical features of patients with 2019 novel coronavirus SARS-CoV-2: a systematic review and meta-analysis. J Med Virol 2020; 63(3). DOI: https://doi.org/10.1002/jmv.25822

27. Di Mascio D, Khalil A, Saccone G, et al. Outcome of coronavirus spectrum infections (SARS, MERS, COVID 1 -19) during pregnancy: a systematic review and meta-analysis. Am J Obstet Gynecol MFM 2020; 2(2): 100107. DOI: https://doi.org/10.1016/j.ajogmf.2020.100107

28. Fu L, Wang B, Yuan T, et al. Clinical characteristics of coronavirus disease 2019 (COVID-19) in China: a systematic review and meta-analysis. J Infect 2020; 80(6): 656-665. DOI: https://doi.org/10.1016/j.jinf.2020.03.041

29. Cheung KS, Hung IFN, Chan PPY, et al. Gastrointestinal manifestations of SARS-CoV-2 infection and virus load in fecal samples from a Hong Kong cohort: systematic review and meta-analysis. Gastroenterology 2020; 159(1): 81-95. DOI: https://doi.org/10.1053/j.gastro.2020.03.065

30. Della Gatta AN, Rizzo R, Pilu G, et al. Coronavirus disease 2019 during pregnancy: a systematic review of reported cases. Am J Obstet Gynecol 2020; 223(1): 36-41. DOI: https://doi.org/10.1016/j.ajog.2020.04.013 
31. Castagnoli R, Votto M, Licari A, et al. Severe acute respiratory syndrome coronavirus 2 (SARS-CoV-2) infection in children and adolescents: a systematic review. JAMA Pediatr 2020 DOI: https://doi.org/10.1001/jamapediatrics. 2020.1467

32. Elshafeey F, Magdi R, Hindi N, et al. A systematic scoping review of COVID-19 during pregnancy and childbirth. Int J Gynaecol Obstet 2020; 150(1): 47-52. DOI: https://doi.org/10.1002/ijgo.13182

33. Rodriguez-Morales AJ, Cardona-Ospina JA, Gutiérrez-Ocampo E, et al. Latin American Network of Coronavirus Disease 2019-COVID-19 Research. Clinical, laboratory and imaging features of COVID-19: a systematic review and meta-analysis. Travel Med Infect Dis 2020; 34: 101623. DOI: https://doi.org/10.1016/j.tmaid.2020.101623

34. Lovato A, de Filippis C. Clinical presentation of COVID-19: a systematic review focusing on upper airway symptoms. Ear Nose Throat J 2020: 145561320920762. DOI: https://doi.org/10.1177/0145561320920762

35. Asadi-Pooya AA, Simani L. Central nervous system manifestations of COVID-19: a systematic review. J Neurol Sci 2020; 413: 116832. DOI: https://doi.org/10.1016/j.jns.2020.116832

36. de Souza TH, Nadal JA, Nogueira RJN, et al. Clinical manifestations of children with COVID-19: a systematic review. Pediatr Pulmonol 2020; 55(8): 1892-1899. DOI: https://doi.org/10.1002/ppul.24885

37. Parohan M, Yaghoubi S, Seraj A, et al. Risk factors for mortality in patients with coronavirus disease 2019 (COVID-19) infection: a systematic review and meta-analysis of observational studies. medRxiv 2020; doi: 10.1101/2020.04.09.20056291

38. Michelen M, Jones N, Stavropoulou C. In patients of COVID-19, what are the symptoms and clinical features of mild and moderate cases?. 2020; https://www.cebm.net/covid-19/in-patients-of-covid-19-what-are-the-symptomsand-clinical-features-of-mild-and-moderate-case (accessed 13 Aug 2020).

39. Burrow MR, Treadwell J, Roberts MN. What clinical features or scoring system, if any, might best predict a benefit from hospital admission for patients with COVID-19? 2020; https://www.cebm.net/covid-19/what-clinical-featuresor-scoring-system-if-any-might-best-predict-a-benefit-from-hospital-admission-for-patients-with-covid-19 (accessed 13 Aug 2020).

40. Khan MMA, Khan MN, Mustagir MG, et al. COVID-19 infection during pregnancy: a systematic review to summarize possible symptoms, treatments, and pregnancy outcomes. medRxiv 2020.

41. Arabi S, Vaseghi G, Heidari Z, et al. Clinical characteristics of COVID-19 infection in pregnant women: a systematic review and meta-analysis. medRxiv 2020.

42. Kahathuduwa CN, Dhanasekara CS, Chin S-H. Case fatality rate in COVID-19: a systematic review and metaanalysis. medRxiv 2020.

43. Xu L, Yaqian M, Chen G. Risk factors for severe corona virus disease 2019 (COVID-19) patients : a systematic review and meta analysis. medRxiv 2020.

44. Heydari K, Rismantab S, Shamshirian A, et al. Clinical and paraclinical characteristics of COVID-19 patients: a systematic review and meta-analysis. medRxiv 2020.

45. Ebrahimi M, Saki A, Rahim F. Laboratory findings, signs and symptoms, clinical outcomes of patients with COVID-19 infection: an updated systematic review and meta-analysis. medRxiv 2020.

46. Ji W, Zhang J, Bishnu G, et al. Comparison of severe and non-severe COVID-19 pneumonia: review and metaanalysis. medRxiv 2020.

47. Jain V, Yuan J-M. Systematic review and meta-analysis of predictive symptoms and comorbidities for severe COVID-19 infection. medRxiv 2020

48. Greenhalgh T, Treadwell J, Burrow R, et al. NEWS (or NEWS2) score when assessing possible COVID-19 patients in primary care? 2020; https://www.cebm.net/covid-19/should-we-use-the-news-or-news2-score-when-assessingpatients-with-possible-covid-19-in-primary-care (accessed 13 Aug 2020).

49. UK Sepsis Trust. GP/ OOH telephone triage sepsis tool. 2018; https://sepsistrust.org/wp-content/uploads/2018/06/ $\mathrm{OOH}$-and-GP-telephone-triage-Adult-NICE-Final-3.pdf (accessed 13 Aug 2020).

50. Royal College of General Practitioners. COVID-19 evidence summary clinical management. 2020; https://elearning. rcgp.org.uk/mod/page/view.php?id=10570 (accessed 13 Aug 2020).

51. Vardavas Cl, Nikitara K. COVID-19 and smoking: a systematic review of the evidence. Tob Induc Dis 2020; 18 : 20. DOI: https://doi.org/10.18332/tid/119324

52. Park M, Cook AR, Lim JT, et al. A systematic review of COVID-19 epidemiology based on current evidence. J Clin Med 2020; 9(4): 967. DOI: https://doi.org/10.3390/jcm9040967

53. Chang T-H, Wu J-L, Chang L-Y. Clinical characteristics and diagnostic challenges of pediatric COVID-19: a systematic review and meta-analysis. J Formos Med Assoc 2020; 119(5): 982-989. DOI: https://doi.org/10.1016/j. jfma.2020.04.007

54. Minotti C, Tirelli F, Barbieri E, et al. How is immunosuppressive status affecting children and adults in SARSCoV-2 infection? A systematic review. J Infect 2020; 81(1): e61-e66. DOI: https://doi.org/10.1016/j.jinf.2020.04. 026

55. Cohen JF, Korevaar DA, Matczak S, et al. COVID-19-related mortality by age groups in Europe: a meta-analysis. medRxiv 2020.

56. Patanavanich R, Glantz SA. Smoking is associated with COVID-19 progression: a meta-analysis. Nicotine Tob Res 2020;.ntaa082. DOI: https://doi.org/10.1093/ntr/ntaa082

57. Matsushita K, Ding N, Kou M, et al. The relationship of COVID-19 severity with cardiovascular disease and its traditional risk factors: a systematic review and meta-analysis. medRxiv 2020.

58. Nasiri MJ, Haddadi S, Tahvildari A, et al. COVID-19 clinical characteristics, and sex-specific risk of mortality: systematic review and meta-analysis. medRxiv 2020.

59. Zhao X, Zhang B, Li P, et al. Incidence, clinical characteristics and prognostic factor of patients with COVID-19: a systematic review and meta-analysis. medRxiv 2020. 
60. Alqahtani JS, Oyelade T, Aldhahir AM, et al. Prevalence, severity and mortality associated with COPD and smoking in patients with COVID-19: a rapid systematic review and meta-analysis. PLoS One 2020; 15(5): e0233147 DOI: https://doi.org/10.1371/journal.pone.0233147

61. Russell B, Moss C, George G, et al. Associations between immune-suppressive and stimulating drugs and novel COVID-19-a systematic review of current evidence. Ecancermedicalscience 2020; 14: 1022. DOI: https://doi.org/10. 3332/ecancer.2020.1022

62. Wang B, Li R, Lu Z, Huang Y. Does comorbidity increase the risk of patients with COVID-19: evidence from metaanalysis. Aging 2020; 12(7).

63. Emami A, Javanmardi F, Pirbonyeh N, et al. Prevalence of underlying diseases in hospitalized patients with COVID-19: a systematic review and meta-analysis. Arch Acad Emerg Med 2020; 8(1): e35.

64. Zuin M, Rigatelli G, Zuliani G, et al. Arterial hypertension and risk of death in patients with COVID-19 infection: systematic review and meta-analysis. J Infect 2020; 81(1): e84-e86. DOI: https://doi.org/10.1016/j.jinf.2020.03.059

65. Yang J, Zheng Y, Gou X, et al. Prevalence of comorbidities and its effects in patients infected with SARS-CoV-2: a systematic review and meta-analysis. Int J Infect Dis 2020; 94: 91-95. DOI: https://doi.org/10.1016/j.ijid.2020.03. 017

66. Huang I, Lim MA, Pranata R. Diabetes mellitus is associated with increased mortality and severity of disease in COVID-19 pneumonia - a systematic review, meta-analysis, and meta-regression. Diabetes Metab Syndr 2020; 14(4): 395-403. DOI: https://doi.org/10.1016/j.dsx.2020.04.018

67. Shamshirian A, Heydari K, Alizadeh-Navaei R, et al. Cardiovascular diseases burden in COVID-19: systematic review and meta-analysis. medRxiv 2020: 20062869.

68. Chen Y, Gong X, Wang L, et al. Effects of hypertension, diabetes and coronary heart disease on COVID-19 diseases severity: a systematic review and meta-analysis. medRxiv 2020.

69. Public Health England. Guidance on shielding and protecting people who are clinically extremely vulnerable from COVID-19. 2020; https://www.gov.uk/government/publications/guidance-on-shielding-and-protecting-extremelyvulnerable-persons-from-covid-19/guidance-on-shielding-and-protecting-extremely-vulnerable-persons-from-covid19 (accessed 13 Aug 2020).

70. Health Protection Scotland. Search criteria for highest risk patients for shielding. 2020; https://hpspubsrepo.blob. core.windows.net/hps-website/nss/3008/documents/1_covid-19-search-criteria-highest-risk-patients.pdf (accessed 13 Aug 2020).

71. Mair FS, May C, O'Donnell C, et al. Factors that promote or inhibit the implementation of e-health systems: an explanatory systematic review. Bull World Health Organ 2012; 90(5): 357-364. DOI: https://doi.org/10.2471/BLT.11. 099424

72. Sheikh A, Cornford T, Barber N, et al. Implementation and adoption of nationwide electronic health records in secondary care in England: final qualitative results from prospective national evaluation in "early adopter" hospitals. BMJ 2011; 343: d6054. DOI: https://doi.org/10.1136/bmj.d6054

73. Bouamrane M-M, Mair FS. A study of general practitioners' perspectives on electronic medical records systems in NHSScotland. BMC Med Inform Decis Mak 2013; 13: 58. DOI: https://doi.org/10.1186/1472-6947-13-58

74. Kazmi Z. Effects of exam room EHR use on doctor-patient communication: a systematic literature review. Inform Prim Care 2013; 21(1): 30-39. DOI: https://doi.org/10.14236/jhi.v21i1.37

75. Mann $C$, Shaw A, Wye L, et al. A computer template to enhance patient-centredness in multimorbidity reviews: a qualitative evaluation in primary care. Br J Gen Pract 2018; 68(672): e495-e504. DOI: https://doi.org/10.3399/ bjgp18X696353

76. de Lusignan S, Dorward J, Correa A, et al. Risk factors for SARS-CoV-2 among patients in the Oxford Royal College of General Practitioners Research and Surveillance Centre primary care network: a cross-sectional study. Lancet Infect Dis 2020. DOI: https://doi.org/10.1016/S1473-3099(20)30371-6

77. Williamson E, Walker AJ., Bhaskaran KJ The OpenSAFELY Collaborative. OpenSAFELY: factors associated with COVID-19-related hospital death in the linked electronic health records of 17 million adult NHS patients. medRxiv 2020.

78. Cahan A, Cimino JJ. A learning health care system using computer-aided diagnosis. J Med Internet Res 2017; 19(3): e54. DOI: https://doi.org/10.2196/jmir.6663

79. BioPortal. COVID-19 surveillance ontology. 2020; https://bioportal.bioontology.org/ontologies/COVID19/?p= summary (accessed 13 Aug 2020).

80. NHS Digital. COVID-19 SNOMED CT codes by groups 20200401v1.0. 2020; https://hscic.kahootz.com/connect.ti/ COVID19_info_sharing/view?objectld=67227941 (accessed 13 Aug 2020).

81. Andrews JE, Patrick TB, Richesson RL, et al. Comparing heterogeneous SNOMED CT coding of clinical research concepts by examining normalized expressions. J Biomed Inform 2008; 41(6): 1062-1069. DOI: https://doi.org/10. 1016/j.jbi.2008.01.010

82. Andrews JE, Richesson RL, Krischer J. Variation of SNOMED CT coding of clinical research concepts among coding experts. J Am Med Inform Assoc 2007; 14(4): 497-506. DOI: https://doi.org/10.1197/jamia.M2372 